\title{
Service Quality of domestic airlines in the face of COVID-19 in Nepal
}

\author{
Gangaram Biswakarma, Achyut Gnawali \\ Assistant Professor \\ Faculty of Management Tribhuvan University Kathmandu \\ Associate Professor \\ Faculty of Management Tribhuvan University Kathmandu
}

\begin{abstract}
The coronavirus pandemic has turned the aviation industry on its head, transforming the passenger experience drastically. The airlines have faced significant challenges due to both the Covid-19 pandemic, the sequence of lockdowns and the provisions of safety and security legislation. There is more concern about the growing feeling that passengers are aware of the level of service. Airlines not only need to focus on service quality in today's highly competitive air transport environment, but also need to focus more on safety and security issues, especially at the time of the Covid-19 pandemic. The research related to these dimensional studies becomes more important in the COVID-19 scenario. Therefore, the objective of this study was to examine the impact of service quality dimensions on the overall quality of service of domestic airlines in Nepal in the midst of the Covid-19 pandemic. A quantitative methodology with a descriptive and explanatory research design was adopted in the study. A sample of 200 passengers recently travelling after the lockdown and reopening of the domestic airline service has been contacted. Out of which 160 responded to the questionnaire. In the sense of COVID-19 post lockdown operations, the service quality of domestic airlines is affected by various factors. All the likely factors that influence the quality of airlines need to be considered by airlines. Reliability, assurance, tangibility, empathy, and responsiveness are the variables. All these aspects play an important role in providing passengers with a reliable service. The dimensions of reliability, tangibility and responsiveness need to concentrate more on having the standard of service as desired in the sense of COVID-19 by domestic airlines in Nepal. It means that during COVID-19 and similar situations, tangibility must concentrate on the highest level of operation.
\end{abstract}

Keywords: COVID-19, Service Quality, Domestic Airlines, Airline Service Quality, Service Delivery, Nepal.

\section{Introduction}

Airlines have emerged as one of the most indispensable travel alternatives in today's age. In the domestic commercial airline market worldwide, the rapid growth of passenger traffic has been experienced. As airlines struggle to acquire and retain clients, rivalry is increasingly growing. Airline service consists of a series of procedures. Passengers at various stages of the service chain can have different standards (Chen and Chung, 2005). The coronavirus pandemic has turned aviation industry on its head and dramatically changed the experience for the passengers. Owing to both the Covid-19 pandemic, series of lockdown and the requirement of safety and security legislation, the airlines have faced great challenges. There is more concern about the rising sense in which passengers are aware of service quality. In today's highly competitive air transport climate, airlines not only need to focus on service quality, but also need to focus more on safety and security issues, especially at the time of the Covid-19 pandemic. The airline industry not only plays a vital role in the service industry, but also contributes to other sectors by carrying passengers around the world to their desired venue (Rhoades \& Waguespack, 2008). Among numerous factors that have affected the passenger growth, service quality plays an important role in the success of the airline industry 
(Bramford \& Xystouri, 2005). Airlines have challenges in the midst of Covid-19 to optimize their service quality protocol with health, safety issues and compliance with international and national agency protocols. As a result, customer satisfaction, loyalty is encouraged, which contributes directly to profitability, market share and return on investment (Fornell, 1992).

Until the end of the Rana regime, Nepal had very limited access to the outside world. In 1949, the formal beginning of aviation in Nepal took place. The Tribhuvan International Airport Nepal Airline Corporation was established in 1958. It was the first and foremost airline in Nepal to provide domestic airlines with flights to Simara, Pokhara and Biratnagar. It links more than 25 destinations within Nepal for domestic operations. In addition, Nepal is a landlocked country, and the mountains cover more than 90 percent of Nepal's territory. Remote areas are cut off from tourism, food supply and other important requirements without the use of air transport. Today, most of Nepal's tourist destinations can be reached by air, from remote airfields to major hub cities, and this facility has significantly enhanced the tourism industry. The Government of Nepal has taken measures to improve the growth of at least the tourism sector by implementing an open-sky policy enabling private airlines to join the domestic air services front.

The principle of service quality is considered paramount in the aviation industry in order to retain and attract new passengers. Therefore, air transport service providers must strive to provide a high quality of service to meet and satisfy a wide variety of customer requirements. This become more of concern in the perspective of Covid-19 situation. In the air travel industry, the quality of airline service is an important issue. While several studies have concentrated in the past on the topic of airline service quality assessment, most of these studies have used the SERVQUAL approach to determine the quality of airline service. However, in the COVID-19 scenario, the analysis relating to these dimensional studies becomes more important. Therefore, the aim of this study was to analyze the effect of dimensions of service quality on achieving overall service quality of domestic airlines in Nepal amidst Covid-19 pandemic.

\section{Literature review}

\section{Service quality of airline services and its measurement}

The quality of service has become a primary area of emphasis for airline companies and other related organizations. Several researchers have studied literature on variables influencing the quality of service on domestic airlines. However, very little research has been reported in the face of COVID-19 in service quality.

In focus to quality, Garvin (1984) defined services that meet customer preferences and expectations are of high quality. In the passenger airline industry, only the customer can truly define service quality (Butler and Keller, 1992). The quality of airline service is difficult to describe and measure due to its heterogeneity, intangibility, and inseparability. Nevertheless, quite a few conceptual and empirical studies have been devoted to investigating the service quality issues in the passenger airline industry. From the perspective of passengers, various schemes for describing service quality dimensions or attributes have been proposed. Most of these programs are presented as quality measures to investigate the ties between the quality of service and related issues, such as airline choice (Ritchie et al., 1980; Etherington and Var, 1984; Wells and Richey, 1996), customer satisfaction (Alotaibi, 1992), customer loyalty (Ostrowski et al., 1993), passenger type (Alotaibi, 1992; White, 1994), airline type (Jones and Cocke, 1981), airline class (Etherington and Var, 1984; Alotaibi, 1992), aircraft type (Truitt and Haynes, 1994), productivity (Ozment and Morash, 1998), total transportation service offering (Morash and Ozment, 1994), assessment group (Gourdin and Kloppenborg, 1991) and attribute dependency (Elliot and Roach, 1993).

The most widely used customer perceived service quality model is perhaps the Gap Analysis and SERVQUAL model by Parasuraman et al. (1985, 1988). However, the conceptualization and evaluation of the standard of a service has long been troublesome for researchers, according to Carman (1990). The problem has been further complicated by service intangibility, simultaneous development and usage and disparities between mechanistic and humanistic efficiency. The SERVQUAL instrument designed to evaluate perceived service quality was then developed by Parasuraman et al. (1985). In the form of five dimensions, the SERVQUAL instrument was operationalized (Parasuraman et al. 1988). The universal implementation of the model has been questioned by Rosen and Karwan (1994), arguing that much depends 
on the degree of customization contained within a service. In service quality analysis, the SERVQUAL model has remained popular amid criticism.

Parasuraman, Zeithaml, and Berry (1988) introduced five dimensions that led to SERVQUAL's growth, these dimensions are as follows: Tangibility: These include the presence of workers, the provision of physical facilities and facilities that are part of the experience of service. Reliability: The manner in which the service is provided, that is, the capacity to reliably and regularly deliver the promised service. Responsiveness: willingness to assist clients, respond to their questions and also provide them with prompt service. Assurance: Awareness and courtesy of employees and their capacity to inspire faith and trust. Empathy: supportive, careful about the requirements of the customers and with compassion, the organization gives individualized attention to its customers.

In the study of Tahanisaz and Shokuhyar (2020) found that passengers' dissatisfaction with service quality is one of the crucial factors affecting the market share loss of airlines. This study was aimed at how airlines become capable of satisfying their passengers by considering the diversity of pre-purchase expectations. Therefore, the study proposes a novel model for clustering air passengers to identify passengers with similar expectations.

According to the study of Shah, Syed, Imam \& Raza (2020), measures the perception of airline service quality based on data collected from Pakistan International Airline (PIA) passengers using SERVQUAL. It investigates the impact of service quality dimensions on passenger's behavioral intentions in presence of mediator (passenger satisfaction). The results reveal that passenger's satisfaction mediates the relationship between airline service quality and behavioral intentions. Likewise, in the study of Lim and Lee (2019), they studied service quality between full-service carriers (FSCs) and low-cost carriers (LCCs). Representing key features of airline service quality, matched to the five typical dimensions used by the SERVQUAL model. The results of the study showed that the most significant dimensions for FSCs and LCCs are tangibles and reliability, respectively. The least significant dimensions are assurance and empathy, respectively. Similarly, Ganiyu (2016) has conducted a study on Perceptions of Service Quality with SERVQUAL Model among Domestic Airline Carriers in Nigeria. The study established that the modified SERVQUAL model provided a satisfactory level of overall reliability in Nigeria's airline context, which implies that all the items were cohesive in forming the SERVQUAL dimensions. The study found that all service quality dimensions are positively and significantly interrelated. The perceived service quality of domestic airlines across these dimensions was found to be poor. The most dissatisfied dimensions in order of ranking were: flight pattern, reliability, facilities, assurance, responsiveness, employee, and customization.

Ayantoyinbo and Boye (2015) made a study to evaluate Nigeria domestic airline services that are preferred by numerous airline passengers in the country. Findings from the study showed that price is the most preferred attribute followed by flight convenience, frequency of flight, comfort and lastly courtesy. The study concluded that airline passengers would prefer domestic airline with particular characteristics which are in order of off-peak price, flight convenience in the morning, frequency of flight for 3 to 4 time daily, good on board comfort and good courtesy from staff. Thus, airline operators need to take the identified attributes preferred by customers very serious in provision of their services. In similar manner, Adeola and Adebiyi (2014) conducted a study on airlines choices, and revealed that the income, poor states of the roads as well as the insecurity accounts for the sudden rise in air transport travelers and that service quality; perceive value influences their satisfaction level on the choice of airline. Likewise, Chilembwe (2014) has conducted case study of Air Malawi. The purpose of the study was to evaluate the level of service quality, value, and satisfaction of Malawi air transportation focusing Air Malawi. The in-depth interviews were conducted with managers and travel industry experts based on SERVQUAL dimensions (tangibles, responsiveness, reliability, assurance and empathy). The results showed that almost all dimensions of customer satisfaction in general were surprisingly mild. Customer and manager outcomes were reasonably similar in efficiency, but also varied in a few ways. The lowest value was found in reliability, which was very critical, such as punctuality and lateness. Baker (2013) conducted a study in which the object of this study was to compare customer satisfaction and quality of service with respect to the quality dimensions of airlines and subsequently to evaluate the relationships between the quality-of-service dimensions and the satisfaction of passengers on airline services. Results show that it was commonly found that the service level of low-cost airlines was higher than that of conventional legacy airlines. Implications were clear relating to 
operating expenses, market share, infrastructure and customer service. Charoensettasilp \& Wu (2013) made a study in Thai passengers for the purpose of studying the service provided by the Thai airlines. It was found that the demographic factors including gender and education do affect Thai passengers' satisfaction after receiving services from Thailand's domestic low-cost airline. In addition to the service marketing mix influence Thai passengers' satisfaction after receiving services from Thailand's domestic low-cost airline. Pabedinskate, Akrtinaite (2013), considers the problems of improvement of the quality of airport services provided to airlines taking into account the changes in consumer needs using SERVQUAL method and established the relative importance of airport service quality assessment criteria in respect of airlines. Alam (2012) investigated the influence of demographic characteristics on brand preference towards budget airlines like Air Arabia in the UAE market. Findings suggest that brand preference does not vary significantly for all the variables in the study. Chickwendu (2012) had made a study on Nigerian airlines using "SERVQUAL" model and it was discovered that aero co tractors airline exhibited a food service quality in the empathy, responsiveness and the technical dimension of their services but the reliability; tangible dimension needs a lot of improvement. Thakor and Mistri (2012) had research carried out during the project had many objectives related to the service quality of the Indian airline industry. In the findings, empathy and tangibility was low in the certain airlines, even though scored well in assurance and responsiveness it was among the lowest service quality. Krishnakumar and Baby (2012) has made a study to know the socioeconomic factors of domestic airline passengers. The study clearly identified that the responsiveness variables are considered to be the most important factors that enhances the airline service quality. In case of domestic airlines services, it is essential to concentrate more on the responsiveness factor to get better service quality level through better services provided by the airlines. Huang (2009) made a study on the effect of airline service quality on passenger's behavioral intentions using SERVQUAL scores. Results indicate that responsiveness is the most important airline service quality attribute in passengers. In addition, the literature analyzed the variables influencing airlines' service efficiency. Studies have been carried out (Chen and Chang, 2005; Correia et al., 2008; De Barros et al., 2007; Fodness and Murray, 2007) showing that passengers feel comfortable when issues such as convenience of details, protection, timeliness of flight, check-in procedures, adequate signage and orientation, and terminal amenities are properly done.

This implies that only few customer satisfaction variables have been found in the aviation industry that have created a void that needs to be filled with overall passenger satisfaction. Handling grievances, however, is part of the development of value and fills gaps between perceived services and anticipated services, and ensures that output exceeds expectations, encouraging greater customer satisfaction. Customer grievances tend to encourage the responsiveness and desire of companies to please consumers, contributing to improved partnerships and increased customer loyalty. Organizations are growing social ties with consumers through individualizing and personalizing customer relationships. The success of upcoming businesses will depend how both satisfied and dissatisfied customers talk about the company's reputation since people tell more of the bad than the good experiences.

Literature analysis shows that Parasuraman, Zeithaml and Berry (1988) have established regardless of the type of services, consumers in many cases assess the same feature of services (five perception dimensions of SERVQUAL).

\section{Theoretical Framework}

The concept of service quality has risen in significance in terms of safety and health during the recent COVID-19 pandemic. Customers are starting to understand more about the overall service concept and are now better able to recognize what the airlines mean by the service level offered in the face of COVID-19. Secondly, researchers are determining ways to measure the level of service. Although the definitions of service quality vary, the definitions are all formulated from the customer perspective: that is, what customers perceive are important dimensions of quality (Lewis, 1989). The Parasuraman, Zeithaml and Berry (1988) model with the service quality dimensions of tangible aspects of service delivery, efficiency, responsiveness, assurance and empathy was adopted in this study.

\section{Methods}

Research design: The study adopted a quantitative approach with a descriptive and explanatory research design. Descriptive research design is adopted to describe the service quality dimensions and explanatory research adopted to explain the effect of dimension on the overall service quality. The study focused on 
finding the factors affecting service quality of domestic airlines in Nepal in the COVID-19 amidst. The population for this study was comprised of passengers travelling through the different domestic airlines of Nepal after resume of the airline services after COVID-19 lockdown in the country. Passengers from different domestic airlines are taken as population for research. Data are collected from the passengers travelling through the six different airlines. The respondents were conveniently selected for administration of the questionnaires using convenience sampling method. A sample of 200 passengers was contacted who recently travelled after the lockdown and reopening of the domestic airline operation. Out of which 160 responded to the questionnaire.

Instrumentation: The study was mainly based on the primary information from the passengers travelling through the different domestic airlines after resume of the airline services after COVID-19 lockdown in the country. A structured questionnaire was utlized to collect data for this research. First part consisted of demographic variables and details of trip, preferred airline of respondents in multiple choice questions. Second part of the questionnaire consist of research variables - reliability, assurance, tangibility, empathy, responsiveness and service quality in five-point rating scale in alignment of the objectives of the study. The questionnaire items were modified according to the COVID-19 scenario of the SERVEQUAL model. The Cornbach's Alpha for the questionnaire was found in the range of 0.885 to 0.831 .

\section{Respondents profile}

Out of total respondents of 160 , there were $55 \%$ males and $45 \%$ females, which shows that the participation of male respondents was more than that of female respondents in the sample size. Majority of the respondent $41.3 \%$ are the age group of 36-45. This is followed by the age group of $26-35$ with $33.1 \%$. Only $8.8 \%$ respondents are the age of more than 46 years. It means majority of the respondents are under the age of 36 45 were travelled in majority in the time of COVID -19 pandemic. Similarly, 3.8\% are high school student, $2.5 \%$ have passed intermediate, $65.6 \%$ have passed bachelor and remaining $28.1 \%$ have passed the master in terms of their educational qualification. The respondents were from different occupations, $15.6 \%$ are student, $76.9 \%$ are employed, $4.4 \%$ are unemployed and $3.1 \%$ are retired. The majority of the respondents are from the income level of 30,000-45,000 followed by the income group of 45,000-60,000.

Table 1 : Respondents profile in percentage

\begin{tabular}{|c|c|c|c|c|c|}
\hline Gender & $\mathbf{N}$ & $\%$ & Age Group & $\mathbf{N}$ & $\%$ \\
\hline Male & 88 & 55 & $16-25$ & 27 & 16.9 \\
\hline Female & 72 & 45 & $26-35$ & 53 & 33.1 \\
\hline Income & $\mathbf{N}$ & $\%$ & $36-45$ & 66 & 41.3 \\
\hline Less than 15,000 & 16 & 11.1 & 46 and above & 14 & 8.8 \\
\hline $15,000-30,000$ & 22 & 15.3 & Qualification & $\mathbf{N}$ & $\%$ \\
\hline $30,000-45,000$ & 47 & 32.6 & High School & 6 & 3.8 \\
\hline $45,000-60,000$ & 43 & 29.9 & Intermediate & 4 & 2.5 \\
\hline 60,000 and above & 16 & 11.1 & Bachelor & 105 & 65.6 \\
\hline Occupation & $\mathbf{N}$ & $\%$ & Masters and above & 45 & 28.1 \\
\hline Student & 25 & 15.6 & \multirow{4}{*}{\multicolumn{3}{|c|}{ Sample: 160 passengers }} \\
\hline Employed & 123 & 76.9 & & & \\
\hline Unemployed & 7 & 4.4 & & & \\
\hline Retired & 5 & 3.1 & & & \\
\hline
\end{tabular}

\section{Results}

The main reason for trip were classified into business, education leisure, health and visiting friends/relatives. The result shows that the reason for taking the trip through the airlines are, 66(41.3\%) were returning to home/ visiting friends and family, 16(10\%) take a trip for education, 42(26.3\%) for health, 5(3.1\%) for leisure and 31(19.4\%) take a trip for business. Most of the respondents take a trip for the business purpose. Likewise, 77(48.1\%) travel through Buddha airlines, 56(35\%) travel through Yeti airlines, 17(10.6\%) travel through Nepal airlines, 2(1.3\%) travel through Simrik airlines, 1(0.6\%) travel through Tara airlines and 
reaming 7(4.4\%) travel through Shree airlines. The majority of the passengers preferred to travel through the Buddha airlines.

The numbers of visits of respondents are classified into first, twice and more than twice after the reoperation time after COVID-19 lockdown. Out of 160 respondents traveled for the first time is $108(67.5 \%), 28(18.1 \%)$ traveled twice and the remaining 23(14.4\%) traveled more than twice. It seems that most of the passengers have traveled first time amidst COVID-19 reoperation of airline service.

Table 4.6

Reason for the trip

\begin{tabular}{|l|l|l|}
\hline Reason for the Trip & Frequency & Percent \\
\hline Business & 31 & 19.4 \\
\hline Education & 16 & 10 \\
\hline Leisure & 5 & 3.1 \\
\hline Health & 42 & 26.3 \\
\hline $\begin{array}{l}\text { Returning to home/ Visiting } \\
\text { Friends and Family }\end{array}$ & 66 & 41.3 \\
\hline
\end{tabular}

Table 4.6

Travelled airline

\begin{tabular}{|l|l|l|}
\hline Traveled Airlines & Frequency & Percent \\
\hline Buddha Airlines & 77 & 48.1 \\
\hline Yeti Airlines & 56 & 35 \\
\hline Nepal Airlines & 17 & 10.6 \\
\hline Simrik Airlines & 2 & 1.3 \\
\hline Tara Airlines & 1 & 0.6 \\
\hline Shree Airlines & 7 & 4.4 \\
\hline
\end{tabular}

Table 4.6

Sequence of travel

\begin{tabular}{|l|l|l|}
\hline Sequence of travel & Frequency & Percent \\
\hline First & 108 & 67.5 \\
\hline Twice & 29 & 18.1 \\
\hline More than twice & 23 & 14.4 \\
\hline & 160 & 100 \\
\hline
\end{tabular}

\section{Status of service quality of the airlines amidst COVID-19}

This part of research explains the descriptive analysis. Five Point Likert Scale questions were asked to passengers of the airlines which scaled from- Strongly Disagree (1) to Strongly Agree (5). The service quality was measured in five dimensions- Reliability, Assurance, Tangibility, Empathy, and Responsiveness. In addition, the Overall Service Quality was measured. The result shows the mean and standard deviation of service quality dimensions. The highest mean value $(M=4.01, \mathrm{SD}=0.505)$ relates to assurance dimension and the lowest $(M=3.17, \mathrm{SD}=0.856)$ relates to responsiveness dimension. It shows assurance is the most important factor as perceived highest agreeableness within the service quality dimensions of the airlines amidst COVID-19 scenario. The overall service quality was represented with mean values of $(M=3.92$, $S D=0.654$ ) which indicates a moderate level of services of airlines amidst COVID-19.

Table $\mathrm{x}$

Descriptive statistics of service quality dimensions 


\begin{tabular}{|l|l|l|l|}
\hline Variables & Mean & Std. Deviation & Result \\
\hline Reliability & 3.85 & .701 & Agree \\
\hline Assurance & 4.01 & .505 & Agree \\
\hline Tangibility & 3.87 & .756 & Agree \\
\hline Empathy & 3.85 & .701 & Agree \\
\hline Responsiveness & 3.17 & .856 & Neutral \\
\hline Service Quality & 3.92 & .654 & Agree \\
\hline
\end{tabular}

Similarly, the result shows that the airlines company provides the targeted quality in time, but the airline company shown sincere interest on solving problem are comparatively low than the targeted quality. As in terms of maintaining the flight timing, most of the airlines fails to provide me on-time flight departures and arrivals. However, this may be due to the traffic conditions in the time-of-flight operations. The airlines provide passengers with well-maintained and sanitized airplanes Personnel working for the airline company that I traveled are neatly dressed in safety norms. The airlines provide safety articles for the passengers. Likewise, the tangibility dimensions of the service quality, the airlines provide passengers with allocated seats to travel. The passengers informed that airlines provide the safety tangibles to its passengers. The passengers are mandatory to wear mask, face shield through the journey. However, the passengers are not provided with food or drinks in flight during the journey as a safety protocol. Daily newspapers and current magazines to read in the airplane are not provided to the passengers. It shows that the utmost efforts are implemented by the airlines to provided safety tangibles to its passengers. Likewise, the assurance dimension of the service quality of domestic airlines of Nepal are ensured in terms of providing the necessary information regarding the flight precautions in terms of COVID-19 protocols and employees are consistently polite with the passenger. The result shows that the airline company provides the necessary information regarding the flight precautions to its passengers. All passengers are assured of measuring body temperature and detail record of their health symptoms like coughing etc. Similarly, the empathy dimension of the service quality shows that the airlines company provides convenient operating hours to all its customers, but the employees do not put themselves in the place of passengers as compared to the convenient operating hours. Airline company shows empathy towards its passengers. Employees of the airlines behave properly with the delayed passengers. Disabled, sick and old peoples are treated properly by the airlines. The airlines are responsiveness towards its passengers. It shows that the employees of the airline company are never too busy to respond to passenger request. Employees of the airlines are always willing to help the passengers.

Likewise, the overall service quality as perceived by the passengers, that the airlines provide well maintained airplanes in terms of sanitizations and other safety protocols. The employees of the airlines are co-operative to help passengers to follow the protocol amidst COVID-19. The passengers are satisfied with the service quality provided by the airline company that they traveled through in COVID-19 period.

Relationship between overall service quality and its dimensions amidst COVID-19

The correlation analysis shows that there is high positive correlation between the dimensions of service quality and overall service quality satisfaction. Pearson correlation coefficient between reliability and service quality of domestic airlines in Nepal is $r=0.8711$, which implies that the two variables are highly positively correlated. Likewise, Pearson correlation coefficient between assurance and service quality of domestic airlines in Nepal is $\mathrm{r}=0.848$, which implies that the two variables are highly positively correlated. Similarly, Pearson correlation coefficient between tangibility and service quality of domestic airlines in Nepal is $r=0.909$, which implies that the two variables are very highly positively correlated. The correlation analysis results shows that Pearson correlation coefficient between empathy and service quality of domestic airlines in Nepal is $r=0.879$, which implies that the two variables are highly positively correlated. Further, Pearson correlation coefficient between responsiveness and service quality of domestic airlines in Nepal is $r$ $=0.897$, which implies that the two variables are highly positively correlated. It implies that all dimensions are significant in terms of the overall service quality satisfaction of passengers. Among the dimensions the Tangibility dimension has highest correlation in COVID-19 scenario. Tangibility in terms of the safety protocols is vital in providing the service quality to the passengers, followed by responsiveness of the 
airlines to the passengers in terms of the safety protocols and service demands in the affairs and situation amidst COVID-109. As such followed by Empathy, Reliability and Assurance.

Table $\mathrm{x}$

Correlation Analysis

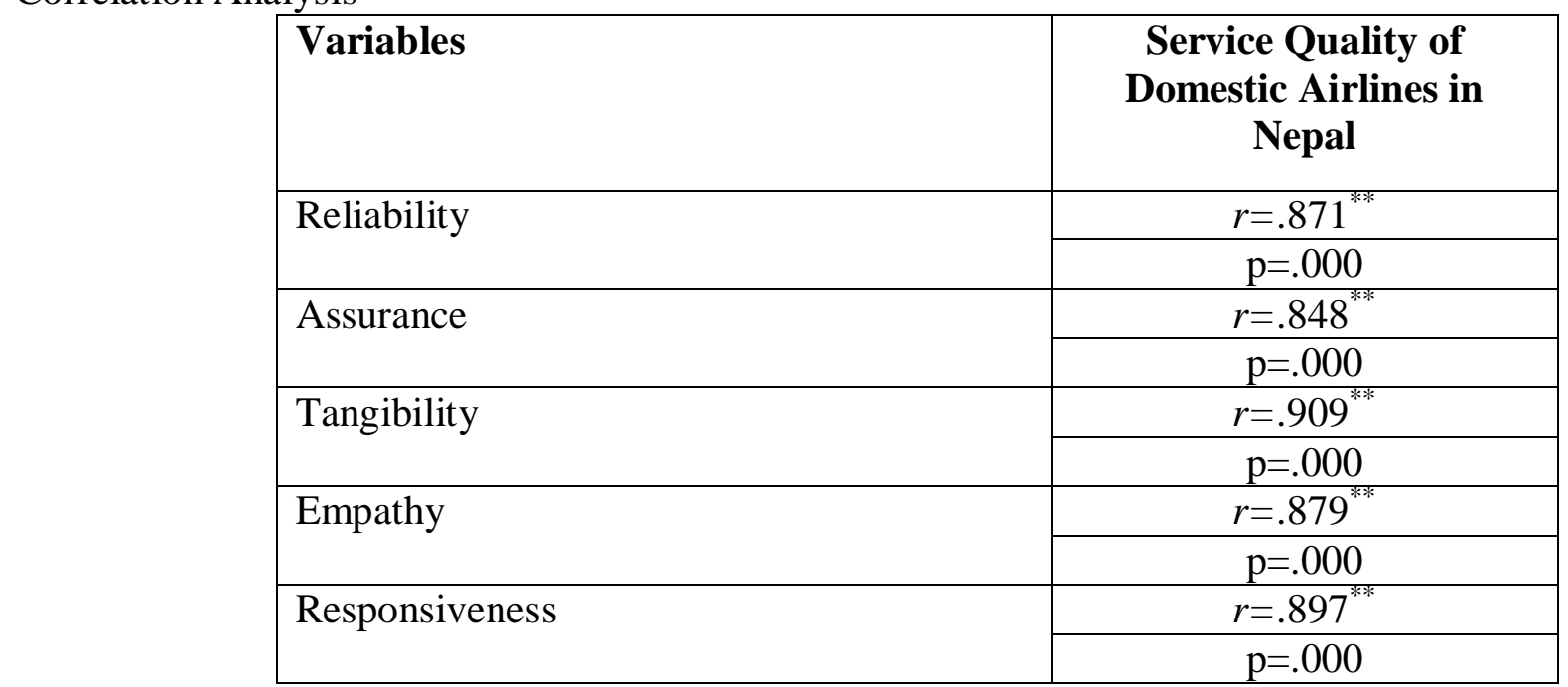

**. Correlation is significant at the 0.01 level (2-tailed).

Impact of the dimension

Multiple regression analysis was used to analyze the impact of dimension of service quality on overall service quality of domestic airlines in Nepal amidst COVID-19 phase. The equation for impact of independent variables is expressed in the following equation: $\hat{\mathrm{Y}}=\alpha+\beta 1 \mathrm{X} 1+\beta 2 \mathrm{X} 2+\beta 3 \mathrm{X} 3+\beta 4 \mathrm{X} 4+\beta 5$ $\mathrm{X} 5+\mathrm{ei}$

Where,

$\hat{\mathrm{Y}}=$ Service Quality; X1 = Reliability; X2 = Assurance; $\mathrm{X} 3=$ Tangibility; $\mathrm{X} 4$ = Empathy; X5= Responsiveness; $\alpha=$ Constant; $\beta 1, \beta 2 \ldots \beta 8=$ Regression coefficients of Factor 1 to Factor 5 respectively; ei $=$ Error term

Based on the coefficients, the regression equation for the service quality of domestic airlines in Nepal can be written as:

Table 4.17

Regression result

\begin{tabular}{|c|c|c|c|c|c|}
\hline $\mathrm{R}$ & R Square & $\begin{array}{l}\text { Adjusted R } \\
\text { Square }\end{array}$ & $\begin{array}{l}\text { Std. Error of the } \\
\text { Estimate }\end{array}$ & $\mathrm{F}$ & Sig. \\
\hline \multirow[t]{3}{*}{0.927} & 0.859 & 0.854 & 0.38134 & 187.258 & 0 \\
\hline & \multicolumn{2}{|c|}{$\begin{array}{l}\text { Unstandardized } \\
\text { Coefficients }\end{array}$} & $\begin{array}{l}\text { Standardized } \\
\text { Coefficients }\end{array}$ & $\mathrm{T}$ & Sig. \\
\hline & $\mathrm{B}$ & Std. Error & Beta & & \\
\hline (Constant) & -0.041 & 0.144 & & -0.283 & 0.778 \\
\hline Reliability & 0.246 & 0.053 & 0.264 & 4.682 & 0.000 \\
\hline Assurance & 0.074 & 0.075 & 0.06 & 0.984 & 0.327 \\
\hline Tangibility & 0.398 & 0.088 & 0.374 & 4.528 & 0.000 \\
\hline Empathy & 0.015 & 0.08 & 0.015 & 0.185 & 0.853 \\
\hline
\end{tabular}




\begin{tabular}{|l|l|l|l|l|l|} 
Responsiveness & 0.284 & 0.078 & 0.276 & 3.653 & 0.000 \\
\hline
\end{tabular}

Predictors: (Constant), reliability, assurance, tangibility, empathy, responsiveness

Dependent Variable: Service Quality

The value of R-square value is 0.85 which means $85 \%$ variation in service quality of domestic airlines in Nepal is explained by reliability, assurance, tangibility, empathy, and responsiveness. Similarly, $\mathrm{F}=187.258$, the p-value is 0.000 which is lesser than alpha value 0.01 . Therefore, the model is a good predictor of the relationship between the dependent and independent variables. As a result, the independent variables (reliability, assurance, tangibility, empathy and responsiveness) are significant in explaining the variance in service quality of domestic airlines in Nepal. Taking five dimensions of service quality of domestic airlines in Nepal i.e. reliability, assurance, tangibility, empathy and responsiveness as independent variable (X1, X2, $\mathrm{X} 3, \mathrm{X} 4, \mathrm{X} 5)$ and service quality of domestic airlines in Nepal as the dependent variable, the regression coefficient of reliability, assurance, tangibility, empathy and responsiveness are 0.246, 0.074, 0.398, 0.015 $\& 0.284$ respectively. The tangibility is important dimension that had an influence on the service quality in COVID-19 phase. The results show the positive impact of reliability, tangibility and responsiveness on the service quality of domestic airlines in Nepal amidst COVID-19. It implicates that tangibility had 39.8\% influence, highest among the five dimensions, followed by responsiveness and reliability. However, the results shows that there is no effect of assurance and empathy on the service quality of domestic airlines in Nepal amidst COVId-19.

\section{Discussion}

The current COVID-19 pandemic has had unprecedented effects on the aviation sector (Tuchen, Arora, \& Blessing, 2020). The main purpose of this study is to examine the factors effecting the service quality of domestic airlines amidst COVID-19 in Nepal. It is also aimed to examine the highest influencing factor that effects the service quality of domestic airlines amidst COVID-19 in Nepal. Survey was conducted among 160 respondents who were the passengers travelling through the different domestic airlines of Nepal. In this research, it is proved that reliability, tangibility, responsiveness, empathy, and assurance play an important role in service quality of the domestic airlines of Nepal, especially in the COVID-19 pandemic period. The findings of the study shows that there is positive effect of reliability on the service quality of domestic airlines in Nepal. There is no positive effect of Assurance on the service quality of domestic airlines in Nepal. There is positive effect of tangibility on the service quality of domestic airlines in Nepal. There is no positive effect of Empathy on the service quality of domestic airlines in Nepal. There is positive effect of responsiveness on the service quality of domestic airlines in Nepal. The findings of this research have proved that different factors affect the service quality of the domestic airlines in Nepal depends on reliability, tangibility and responsiveness amidst COVId-19. The tangibility is important dimension that had an influence on the service quality in COVID-19 phase. This finding is aligned with the study of Tuchen, Arora, \& Blessing (2020), where it was mentioned that, while the majority of passengers may benefit from airports vying for their business through better amenities and the like, on an individual level, a significant proportion of them are, no doubt, also left out. It is also supported the findings of Krishnakumar and Baby (2012) and Huang (2009), in which it was found that the responsiveness variables are considered to be the most important factors that enhances the airline service quality. In case of domestic airlines services it is essential to concentrate more on the responsiveness factor to get better service quality level through better services provided by the airlines. The airline companies need to analyze the different dimensions of the service quality for the success of the business with following the protocol on COVID-19. It has an alignment in gereral situation with the study of Ganiyu (2016) studied about the service quality dimensions in the Nigerian airline industry. Researcher found that all the dimensions of the service quality are positively and significantly co-related. Tahanisaz and Shokuhyar (2020), Lim and Lee (2019), Shah, Syed, Imam, \& Raza (2020) and Nitin \& PremVrat, (2017) in their study identified that the different factors like reliability, tangibility, responsiveness, empathy assurance affect the service quality of the airlines. Likewise, in this research also most of the dimensions have positive relation with the service quality. Reliability, tangibility, and responsiveness positively affect the service quality. The findings are aligned with the study of Lim and Lee (2019), which results showed that the most significant dimensions for FSCs and LCCs are tangibles and reliability, respectively. The least significant dimensions are assurance and empathy, respectively. By 
comparing extracted features in detail, they found specific differences in traveler perceptions between FSCs and LCCs. Researcher found that all the five dimensions are important factors which affect the service quality of the domestic airlines. In this research also all the dimensions have mean more than 3 , that means all the dimensions play an important role in the service quality of the domestic airlines in Nepal in the face of COVID-19. Chilembwe (2014) has conducted case study of air Malawi they found reliability such as punctuality and lateness which were very crucial.

\section{Conclusion}

The service quality of the domestic airlines is affected by the different factors in amidst COVID-19 post lockdown operation. Airlines need to consider all the probable factors which affect the quality of the airlines. The factors are reliability, assurance, tangibility, empathy, and responsiveness. All these factors play an important role in providing the quality service to the passengers. The dimensions - reliability, tangibility and responsiveness need to focus more to get the service quality as desired of domestic airlines in Nepal amidst COVID-19. It implicates that tangibility need to focus the highest for the service quality in amidst COVID-19 and alike situation. However, each of the factors delivers the proper quality service to the passengers, therefore, need to be considered for the best service quality of the airlines during COVID-19 and alike situation.

\section{Reference}

[1] Adeola, M. M., \& Adebiyi, S. O. (2014). Service quality, perceived value and customer satisfaction as determinant of airline choice in Nigeria. International Letters of Social and Humanistic Sciences, 20, 66-80.

[2] Alam, M. (2012). Demographic influences on brand preferences towards budget airlines in UAE.International Journal of Applied Research and Studies, 1 (2), 178.

[3] Ayantoyinbo, B. B. (2015). Assessing the impact of Information and Communication Technology (ICT) on the performance of freight distribution. European Journal of Logistics Purchasing and Supply Chain Management, 3(3), 1-11.

[4] Alotaibi, K. F. (1992). An empirical investigation of passenger diversity, airline service quality, and passenger satisfaction. http://www.trb.org/AnnualMeeting/AnnualMeeting.aspx

[5] Baker, T. A. Byon, K. K., \& Zhang, J. J. (2013). Impact of core and peripheral service quality on consumption behavior of professional team sport spectators as mediated by perceived value. European Sport Management Quarterly, 13(2), 232-263.

[6] Bamford, D., \& Xystouri, T. (2005). A case study of service failure and recovery within an international airline. Managing Service Quality: An International Journal. 15(3), 306-322.

[7] Butler, G. F., \& Keller, M. R. (1992). The cost-constrained global airline industry environment: what is quality?. Transportation Quarterly, 46(4).

[8] Carman, J. M. (2000). Patient perceptions of service quality: combining the dimensions. Journal of services marketing. 33(2), 134-163.

[9] Charoensettasilp, S., \& Wu, C. (2013). Thai Passengers "e Satisfaction after Receiving Services from Thailand's Domestic Low Cost Airline. International Journal of u-and e-Service, Science and Technology, 6(6), 107-120.

[10] Chen, F. Y., \& Chang, Y. H. (2005). Examining airline service quality from a process perspective. Journal of Air Transport Management, 11(2), 79-87.

[11] Chikwendu, D. (2012). Evaluation of service quality of Nigerian airline. Journal of Hospitality Management and Tourism, 3, 117-125.

[12] Chilembwe, J. M. (2014). Evaluation of service quality, value of satisfaction and air transportation in Malawi: A case study for Malawi Airlines. International Journal of Hospitality Management and Tourism, 3, 117-125.

[13] Correia, A., Kozak, M., \& Ferradeira, J. (2008). From tourist motivations to tourist satisfaction. International Journal of Culture, Tourism and Hospitality Research. 19(1), 106-134.

[14] De Barros, A. G., Somasundaraswaran, A. K., \& Wirasinghe, S. C. (2007). Evaluation of level of service for transfer passengers at airports. Journal of Air Transport Management, 13(5), 293-298.

[15] Elliott, K. M., \& Roach, D. W. (1993). Service quality in the airline industry: are carriers getting an unbiased evaluation from consumers?. Journal of Professional Services Marketing, 9(2), 71-82. 
[16] Etherington, L. D., \& Var, T. (1984). Establishing a measure of airline preference for business and nonbusiness travelers. Journal of Travel Research, 22(4), 22-27.

[17] Fodness, D., \& Murray, B. (2007). Passengers' expectations of airport service quality. Journal of Services Marketing. 21(7), 492-506.

[18] Fornell, C. (1992). A national customer satisfaction barometer: The Swedish experience. Journal of marketing, 56(1), 6-21.

[19] Ganiyu, R. A. (2016). Perceptions of Service Quality: An Empirical Assessment of Modified SERVQUAL Model among Domestic Airline Carriers in Nigeria. Acta Universitatis Sapientiae, Economics and Business, 4(1), 5-31.

[20] Garvin, D. A. (1984). Product quality: An important strategic weapon. Business horizons, 27(3), 4043.

[21] Gourdin, K. M., Gourdin, K. N., \& Kloppenborg, T. J. (1991). Identifying service gaps in commercial air travel: the first step toward quality improvement. Transportation Journal, 22-30.

[22] Huang, Y. K. (2010). The effect of airline service quality on passengers' behavioural intentions using SERVQUAL scores: A Taiwan case study. Journal of the Eastern Asia Society for Transportation Studies, 8, 2330-2343.

[23] Jones, J. R., \& Cocke, S. I. (1981). A performance evaluation of commuter airlines: the passenger's view. In Proceedings, Transportation Research Forum (Vol. 22).

[24] Krishnakumar, D., \& Baby, P. (2012). Role of responsiveness factor in enhancing domestic airlines service quality. Indian Journal of Applied Research, 2(1), 293-317.

[25] Lewis, B. R. (1989). Quality in the service sector: a review. International Journal of Bank Marketing. 7(5), 4-12.

[26] Lim, J., \& Lee, H. C. (2020). Comparisons of service quality perceptions between full service carriers and low cost carriers in airline travel. Current Issues in Tourism, 23(10), 1261-1276.

[27] Morash, E. A., \& Ozment, J. (1994). Toward management of transportation service quality. Logistics and Transportation Review, 30(2), 115.

[28] Ostrowski, P. L., O'Brien, T. V., \& Gordon, G. L. (1993). Service quality and customer loyalty in the commercial airline industry. Journal of travel research, 32(2), 16-24.

[29] Ozment, J., \& Morash, E. A. (1998). Assessment of the relationship between productivity and performance quality in the US domestic airline industry. Transportation research record, 1622(1), 22-31.

[30] Pabedinskaitè, A., \& Akstinaite, V. (2014). Evaluation of the airport service quality. Procedia-Social and Behavioral Sciences, 110, 398-409.

[31] Parasuraman, A., Zeithaml, V. A., \& Berry, L. L. (1985). A conceptual model of service quality and its implications for future research. Journal of marketing, 49(4), 41-50.

[32] Parasuraman, A., Zeithaml, V. A., \& Berry, L. (1988). SERVQUAL: A multiple-item scale for measuring consumer perceptions of service quality. 1988, 64(1), 12-40.

[33] Rhoades, D. L., \& Waguespack, B. (2008). Twenty years of service quality performance in the US airline industry. Managing Service Quality: An International Journal. 18(1), 20-33.

[34] Ritchie, J. B., Johnston, E. E., \& Jones, V. J. (1980). Competition, fares and fences-perspective of the air traveler. Journal of Travel Research, 18(3), 17-25.

[35] Rosen, L. D., \& Karwan, K. R. (1994). Prioritizing the dimensions of service quality: an empirical investigation and strategic assessment. International Journal of Service Industry Management, 5(4), 39-52.

[36] Shah, F. T., Syed, Z., Imam, A., \& Raza, A. (2020). The impact of airline service quality on passengers' behavioral intentions using passenger satisfaction as a mediator. Journal of Air Transport Management, 85, 101815.

[37] Tahanisaz, S. (2020). Evaluation of passenger satisfaction with service quality: A consecutive method applied to the airline industry. Journal of Air Transport Management, 83, 101764.

[38] Shah, F. T., Syed, Z., Imam, A., \& Raza, A. (2020). The impact of airline service quality on passengers' behavioral intentions using passenger satisfaction as a mediator. Journal of Air Transport Management, 85, 101815. 
[39] Thakor, C., \&Mistri, K. (2012). Consumer behavior concerning service quality and various dimensions of service provided by airlines. International Monthly Referred Journal of Research in Management and Technology, 1, 3-25.

[40] Truitt, L. J., \& Haynes, R. (1994). Evaluating service quality and productivity in the regional airline industry. Transportation Journal, 21-32.

[41] Tuchen, S., Arora, M., \& Blessing, L. (2020). Airport user experience unpacked: Conceptualizing its potential in the face of COVID-19. Journal of air transport management, 89, 101919.Wells, A. T., \& Richey, F. D. (1996). Commuter airlines.

[42] White, M. D., Abels, E. G., \& Nitecki, D. (1994). Measuring Customer Satisfaction and Quality of Service in Special Libraries. 